\title{
AVALIAÇÃO DO ESTAGIÁRIO NA FORMAÇÃO DOCENTE NO PROGRAMA ESPECIAL DE GRADUAÇÃO PARA A EDUCAÇÃO TÉCNICA E PROFISSIONAL DA UFSM \\ http://dx.doi.org/10.5902/2318133838573
}

\author{
Paula Donaduzzi Rigo ${ }^{1}$ \\ Rafael Marcuzzo² \\ Aruna Noal Correa ${ }^{3}$
}

\begin{abstract}
Resumo
Neste trabalho apresenta-se o relato de experiência de estágio de dois egressos do Curso de Formação de Professores para a Educação Profissional, mantido pela UFSM. Nessa perspectiva, apresenta-se a contribuição da avaliação dos estagiários para discutir os pontos positivos e as necessidades de melhoria no decorrer da formação docente. Conclui-se que o processo de avaliação é fundamental, tanto para a formação de professores, quanto para a atividade docente e, sobretudo, o estudo serve de base reflexiva para os profissionais docentes nas áreas de bacharelado, questionando a validade de processos auto-avaliativos acerca da ação docente, bem como para ressaltar a importância de acompanhamento dos estagiários durante sua atuação em campo de estágio e o feedback constante sobre sua atuação frente aos alunos.

Palavras-chave: avaliação; formação de professores; educação profissional.

\section{TRAINEE EVALUATION IN THE TEACHER LEARNING IN THE SPECIAL PROGRAM OF GRADUATION FOR THE TECHNICAL AND PROFESSIONAL EDUCATION}

\section{Abstract}

This work presents the report of the teaching experience of two graduates of the teacher learning course for professional education. From this perspective, we give the contribution of the trainees' evaluation to discuss the positive points and the needs for improvement during the teacher training. It is concluded that the evaluation process is fundamental both for teacher training and for teaching activity. And, above all, the study serves as a reflexive basis for teaching professionals in the areas of baccalaureate, questioning the validity of self-evaluation processes about the teaching, as well as to highlight the importance of accompanying the trainees during their work in the field of internship and constant feedback on their performance vis-à-vis students.

Key-words: evaluation; teacher training; professional education.

\footnotetext{
1 Universidade Federal de Santa Maria, Brasil. E-mail: pauladonaduzzi@gmail.com.

2 Universidade Federal de Santa Catarina, Brasil. E-mail: rafael.marcuzzo@gmail.com.

3 Universidade Federal de Santa Maria, Brasil. E-mail: arunanoal@hotmail.com.

\begin{tabular}{l|l|l|l|l|l|l} 
Regae: Rev. Gest. Aval. Educ. & Santa Maria & v. 8 & n. 17 & Pub. contínua 2019 & p. 1-14
\end{tabular}
}




\section{Introdução}

1 maior responsabilidade no cumprimento das expectativas da sociedade quanto a educação recai sobre o professor (Tarhnan, 2015). O professor possui uma atuação complexa, envolvendo diversos elementos em um mesmo ambiente, necessidade de tomar decisões e controlar situações (Machado, 2007). Associando essa complexidade a responsabilidade da atuação do professor, a formação de professores é a ferramenta para enfrentar os desafios da educação (Spear; Costa, 2018). Considerando as distintas áreas de conhecimento, não há significativa diferença em relação à atuação docente, mas, apesar disso, ela é demarcada a partir da área de conhecimento dos docentes, ou seja, o conhecimento pedagógico se ajusta às diferentes áreas do conhecimento, tomando corpo como um conhecimento pedagógico específico (Scremin; Isaia, 2018).

No entender de Pachane e Pereira (2004), quando se cita formação de professores é comum a conotação de formação de docentes para a educação básica e, dificilmente, compreende-se a necessidade de formação de professores para os demais níveis de educação. Porém, relatos de que o professor sabe a matéria, mas não sabe transmiti-la aos alunos é frequente (Pachane; Pereira, 2004). Isso ocorre porque, por muitos anos, existiu a concepção de que o conhecimento teórico ou experiência na área eram suficientes para ser um bom professor (Castaman; Vieira; Oliveira, 2016). A partir dessa concepção, dentre os professores que atuam em escolas profissionais, inúmeros docentes possuem apenas bacharelado, sem nenhuma formação pedagógica (Castaman; Vieira; Oliveira, 2016).

Para enfrentar isso foi proposta a resolução CNE/CEB n. 02/97 (Brasil, 1997), que trata da preparação por meio de programas especiais de formação pedagógica de professores para a educação profissional, possibilitando programas de formação para esses professores. Neste contexto insere-se o Programa Especial de Graduação de Formação de Professores para Educação Profissional - PEG - da Universidade Federal de Santa Maria. O PEG/UFSM atende a demanda de formação pedagógica na área de atuação do profissional no âmbito da educação profissional, principalmente, na educação técnica de nível médio da educação básica (UFSM, 2015). Nesse programa são desenvolvidos três estágios supervisionados, e no terceiro estágio o aluno em formação deve ministrar trinta horas de aulas para cursos de educação profissional (UFSM, 2015).

O estágio é o momento de grande expectativa dos alunos em formação pedagógica, pois, na maioria das vezes, é a primeira ocasião que assumem a condição de professores (Milanesi, 2012). O estágio é regido pela lei $\mathrm{n}$. 11.788/2008, que o define como o ato educativo escolar supervisionado, desenvolvido no ambiente de trabalho, que objetiva preparar para o trabalho produtivo de educandos (Brasil, 2008). É denominado estágio supervisionado, pois é orientado por uma visão crítica de pedagogia, concretizando a ação docente consciente, deliberada e responsiva às mudanças (Vieira, 2009). Por isso, esse processo deve ser avaliado de forma intensa para compreender se os objetivos da aprendizagem prática foram atingidas. Para tanto, a avaliação do estagiário se apresenta como estratégia do aprender a como aprender.

A estruturação básica da avaliação do estágio deve focar na articulação entre as ações docentes cotidianas, que são constituídas pelos estagiários, mediadas pelo orientador e analisada pelo supervisor, sustentados por premissas reflexivas (Rocha; 
Abegg; Rela, 2015). Isso porque a formação de professores precisa concentrar-se no desenvolvimento de competências estratégicas e impulsionar o pensamento críticoreflexivo. Por isso, no processo de estágio, é necessário exercitar a reflexão crítica sobre a prática docente para enriquecer a formação do professor (Freire, 1996). Nessa esfera é preciso entender que a pedagogia universitária se constitui a partir da tensão entre os conhecimentos científicos da área e os conhecimentos pedagógicos. Tal compreensão indica que os saberes acadêmicos são construídos no enfrentamento dessas tensões e na constante busca de convergência entre os interesses da área específica, da área pedagógica e da dinâmica do mundo do trabalho (Scremin; Isaia, 2018).

Destaca-se que pesquisas que se concentram em analisar formas de avaliação de estagiários em regência são escassos. Nesse sentido, o objetivo deste artigo é discutir a importância da avaliação dos estagiários na formação docente no Programa Especial de Graduação para a Educação Técnica e Profissional pela aplicação de três instrumentos de avaliação. Além da avaliação do estagiário em processo formativo, o objetivo de uma supervisão docente é auxiliar os formandos a tornar-se supervisores de sua própria prática profissional (Vieira, 2009).

\section{Metodologia}

Dois estagiários formados em Engenharia de Produção realizaram estágio no Curso Técnico em Segurança do Trabalho, mantido pelo Colégio Técnico Industrial de Santa Maria - Ctism -, sob a supervisão do mesmo professor, nas Disciplinas de Ergonomia, estagiário 1, e Administração e Organização do Trabalho, estagiário 2.

O Ctism é uma escola técnica vinculada à Coordenadoria de Educação Básica, Técnica e Tecnológica da Universidade Federal de Santa Maria, fazendo parte, no âmbito do Sistema Federal de Ensino, da Rede Federal de Educação Profissional, Científica e Tecnológica, a qual é subordinada ao Ministério da Educação. Tem por finalidade a oferta de educação profissional e tecnológica nos diferentes níveis e nas distintas modalidades de ensino, de modo a articular as dimensões do trabalho, da ciência e da tecnologia.

Localizado nas proximidades da principal via de acesso da UFSM, o Ctism tem como missão promover a Educação Profissional, desenvolvendo conhecimento humano e tecnológico. Os cursos ofertados são de formação inicial e de formação continuada, de educação profissional técnica de nível médio e de educação profissional tecnológica de graduação e de pós-graduação. O curso Técnico em Segurança do Trabalho pertence ao Eixo Tecnológico Controle e Processos Industriais e as disciplinas que compõem a estrutura curricular estão distribuídas em quatro semestres letivos.

Ambos estagiários realizaram trinta horas de regência, previstas pelo curso de formação pedagógica, e executaram três metodologias de auto avaliação: (1) diário de relato, em que os estagiários realizaram uma reflexão de suas performances em cada uma das aulas; (2) aplicação de um questionário de avaliação aos alunos; e (3) aplicação de uma ficha de avaliação do estagiário pelo professor supervisor. Cazetta et al. (2018) ratificam ao afirmarem que a imersão no ambiente educacional, possibilitada pela permanência dos estagiários numa mesma escola, possibilita aos estagiários desnaturalizar as concepções do que possa ser a escola pública a partir das suas experiências. 
Os relatos dos estagiários, por configurarem-se como diários pessoais de reflexão sobre os sentimentos, atitudes e situações durante a experiência docente, não seguiram estrutura fixa. Por isso, trechos desses diários foram utilizados para discutir os demais resultados, como apoio as outras duas avaliações utilizadas no presente artigo. Destacase que os dois questionários de avaliação seguiram estruturas fixas. $O$ questionário respondido pelos alunos apresenta questões fechadas mensuradas em uma escala likert de cinco pontos, em que 1 equivale a discordo totalmente e 5 concordo totalmente. Nesse questionário três eixos de atuação são avaliados por cinco indicadores compondo cada eixo. A Figura 1 apresenta o resumo dos indicadores avaliados.

Figura 1 -

Eixos e indicadores da avaliação do estagiário pelo discente.

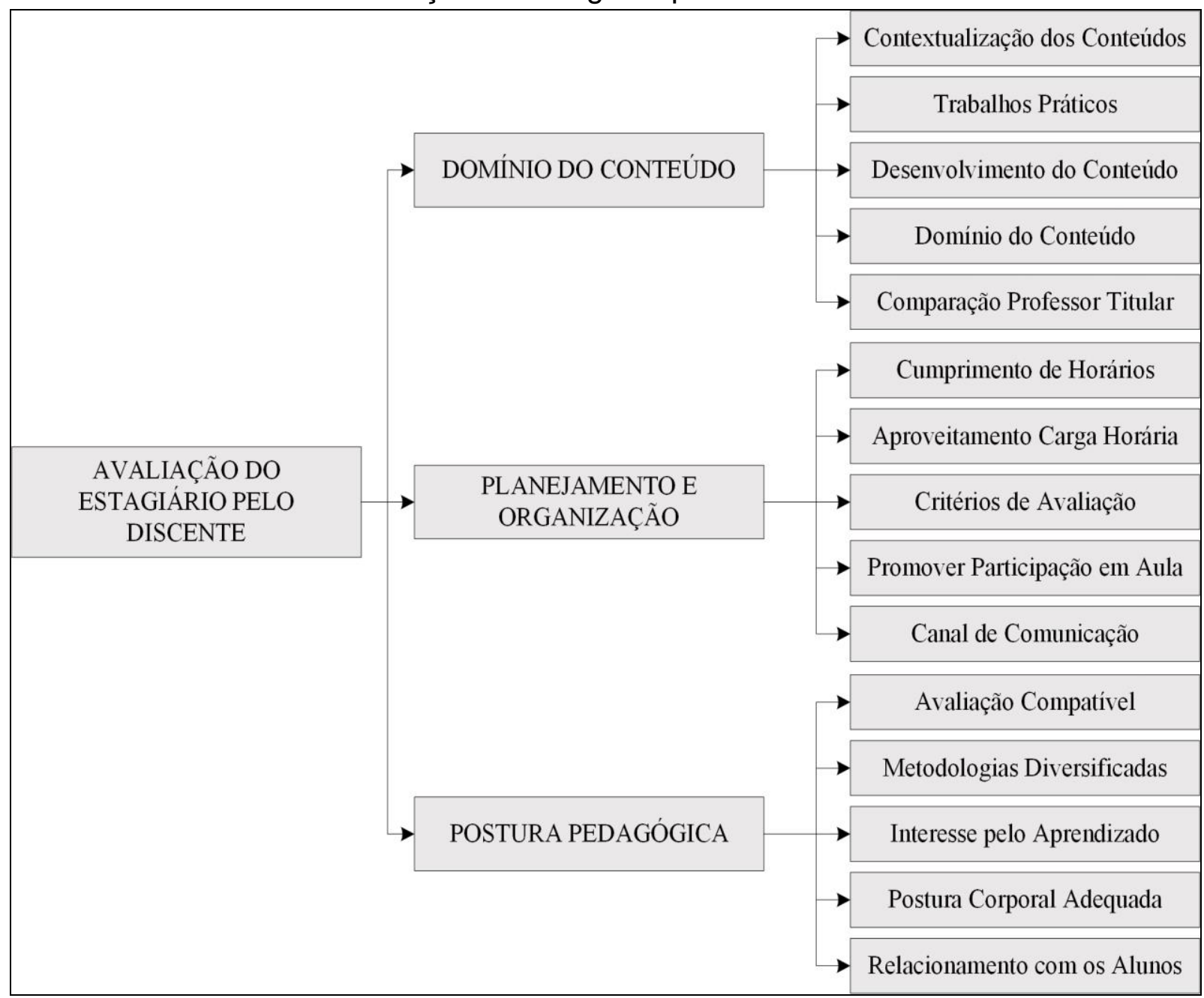

Fonte: dados da pesquisa.

Os três eixos envolvem o domínio do conteúdo, o planejamento e organização e a postura pedagógica dos estagiários. As 15 questões associadas a esses eixos buscam mensurar o nível ao qual os estagiários se encontram. Esse é o feedback para que os professores em formação possam saber quais dos 15 pontos devem focar o seu desenvolvimento futuro e refletir sobre sua atuação. O estagiário 1 atuou na disciplina de Ergonomia e teve um total de 18 alunos. O estagiário 2 atuou na disciplina de Administração e Organização do Trabalho e teve um total de 19 alunos. 
O próximo questionário é a avaliação do professor titular (supervisor de estágio) sobre a atuação dos estagiários em regência. Esse é formulado pelo PEG/UFSM e faz parte da avaliação da disciplina de Estágio Supervisionado III. O professor titular mensura de 0 a 10 em quatro eixos de avaliação: (1) Domínio do conhecimento na área específica de atuação, com cinco indicadores; (2) Planejamento de Situação de Ensino, também com cinco indicadores; (3) Comunicação, com três indicadores; e (4) Compromisso, com quatro indicadores. Esse questionário auxilia os estagiários a compreenderem quais os pontos devem ser melhorados em sua atuação como colega e professor através da visão de um professor experiente e situado no contexto escolar do estágio.

\section{Perfil dos alunos}

Como o contexto escolar é o mesmo técnico profissionalizante, o perfil de ambas turmas eram muito parecidos, conforme pode ser observado na Figura 2. Do total de 37 alunos $57 \%$ são do sexo feminino e $43 \%$ do sexo masculino, o que pode ser considerado um curso misto. Poucos alunos possuem conhecimentos práticos na área do curso técnico, declarando não atuar nesse cenário profissional (78\%).

Figura 2 -

Perfil dos alunos.

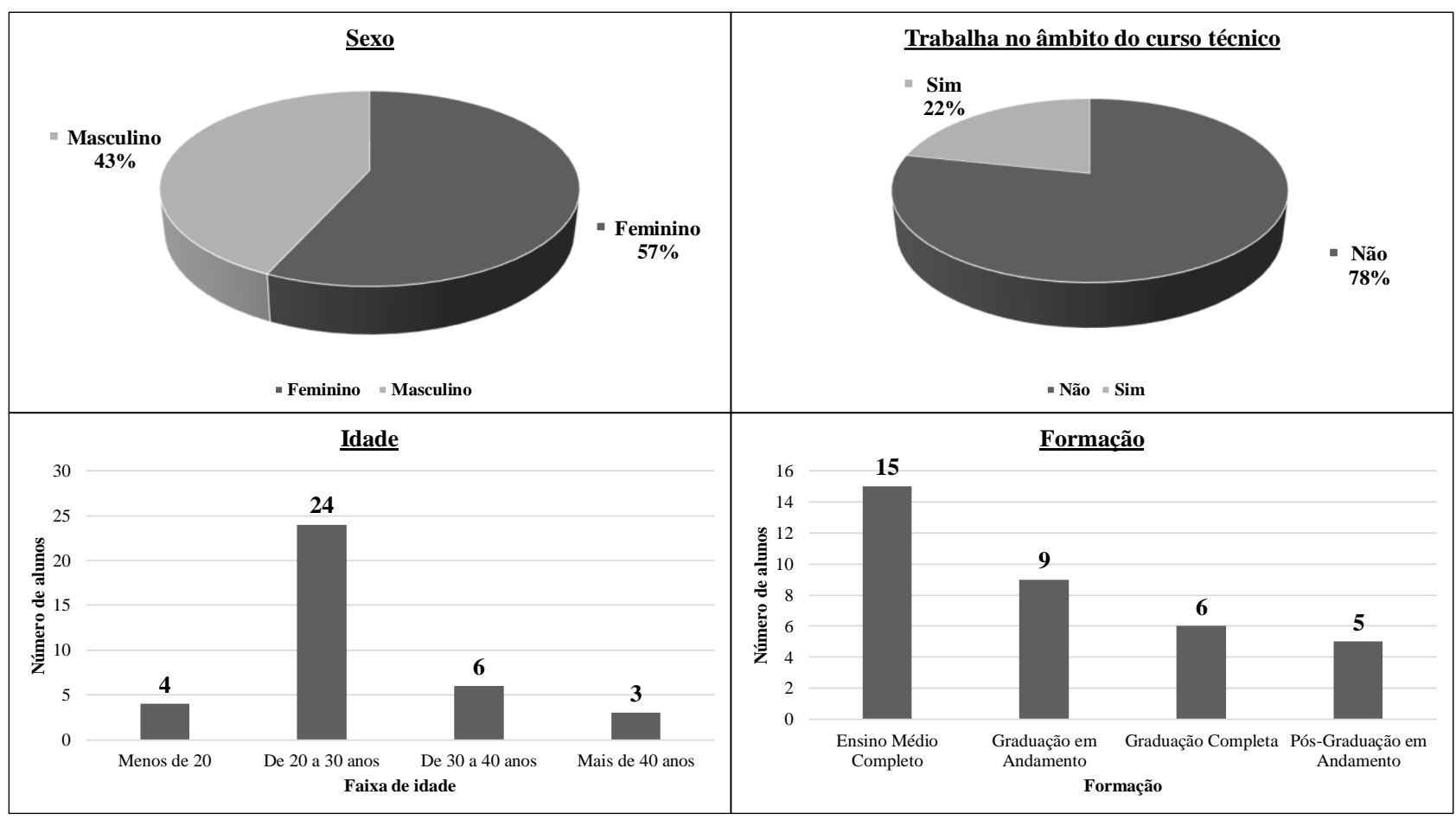

Fonte: dados da pesquisa.

A maioria dos alunos estão na faixa etária dos 20 aos 30 anos, na mesma faixa etária dos estagiários. Apenas quatro alunos possuem menos de 20 anos e nove alunos mais de 30 anos. O nível de escolaridade dos alunos é variado, sendo que por ser um curso pós ensino médio, menos da metade dos alunos permanecem apenas com o ensino 
médio. Isso acontece porque a cidade de Santa Maria é um local de muitas instituições de ensino superior, incluindo a UFSM, e os alunos buscam aprimorar seus conhecimentos. É interessante ressaltar que cinco alunos estão no mesmo nível de escolaridade que os alunos estagiários, o de pós-graduação em andamento.

\section{Domínio do conteúdo}

O primeiro eixo de análise é o Domínio do conteúdo. Os cinco indicadores que o compõe podem ser visualizados na Figura 3, em que o primeiro gráfico apresenta as notas do estagiário 1 e o segundo gráfico as notas do estagiário 2.

Figura 3 -

Domínio do conteúdo.

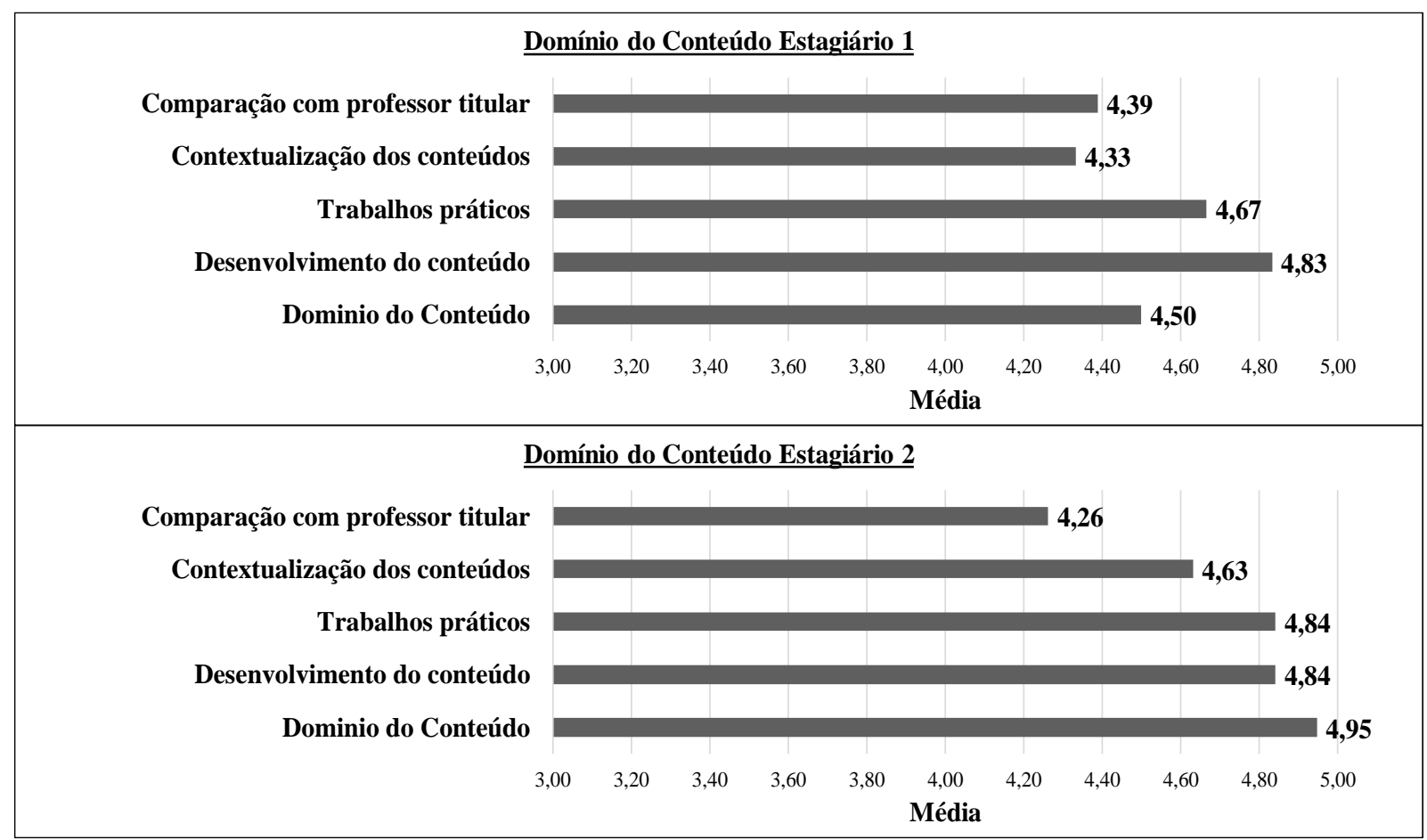

Fonte: dados da pesquisa.

Para o estagiário 1 o "Desenvolvimento do conteúdo" e os "Trabalhos práticos" foram indicadores que lideraram em nível de satisfação. Durante os planejamentos de aulas, buscou-se iniciar as mesmas com um desafio inicial que fosse atualizado e condizente com a realidade do contexto dos formandos. Foram utilizadas notícias de jornais e agências governamentais, além de imagens e pequenos filmes. As atividades buscavam integrar os alunos ao tema que seria tratado na aula e coletar respostas criativas aos problemas apresentados, geralmente efetivados através de diálogos e, por vezes, realizado através da entrega de atividade escrita. Acerca da proposta desenvolvida, segue trecho de relato sobre a reação dos alunos: "surpresos com a ideia de ter um desafio inicial explícito para a aula; porém, aderiram prontamente e demonstraram interesse nessa estrutura, mesmo que apresentando deficiências ao colocarem-se verbalmente e por escrito, porém sempre apresentaram pontos de vistas 
relevantes" (aula 1 - estagiário 1). Inclusive, em decorrência do narrado, houve ênfase na melhoria do emprego da gramática e ortografia dos alunos, fator relatado com preocupação devido a emergência de ser sanado, ou seja, a visível fragilidade formativa nas disciplinas de Português e Matemática.

Em relação a "Comparação com o professor titular", o estagiário 1 recebeu valores menores, mas ainda acima da média. Isso significa que a maioria considerou a atuação do estagiário satisfatória, respondendo a demanda por trabalhar os conteúdos, assim como, aplicar técnicas de ensino perspicazes, apesar de não ter obtido níveis máximos de comparação (5), ficando com 4,39. Nesse quesito, segue o relato de uma aluna considerada exemplar: "professor responsável e disposto a ministrar aulas" (aula 5 estagiário 1 - aluna, A.).

O estagiário 2 obteve uma média baixa em comparação com o professor titular pois os alunos não conheciam o professor e não poderiam avaliar, informando como a nota 3 indiferente. Devido à falta de experiência na área de tecnologia em segurança do trabalho, o estagiário 2 apresentou dificuldade em contextualização dos conteúdos com o cenário profissional e os alunos perceberam essa carência, apontada pelo indicador 2 . $\mathrm{Na}$ primeira aula o estagiário relatou que "devido a minha ansiedade, dei a aula planejada em pouco tempo, e por isso, iniciei a próxima aula. Isso fez com que a aula ficasse cansativa, com muitos slides e pouca fixação do conteúdo. Isso aconteceu porque, por ser a primeira aula, a turma ainda não estava disposta a discutir o conteúdo" (aula 1 - estagiário 2). A reflexão do estagiário demonstra a sensibilidade em compreender que a experiência da docência também se faz no cotidiano, refletindo sobre as situações de ensino e colocando-se no lugar do aluno. Ainda, destaca-se que esse cenário inicial dificultou o relacionamento com os alunos da turma nas aulas posteriores, tanto no que se relaciona a segurança do estagiário, quanto na aceitação e compreensão acerca do docente em formação, por parte dos alunos.

Em relação ao desenvolvimento do conteúdo, o estagiário 2 identificou que os alunos gostavam de questões de concursos, pois era o grande objetivo deles, por isso, relatou que "para que eles fixassem o conteúdo, entreguei uma folha de questões de concurso para cada um. Deixei que eles trabalhassem por um tempo e depois corrigimos todos juntos. Foi uma boa aula, em que não trouxe conteúdos novos, mas trabalhamos os conteúdos da aula passada de forma objetiva" (aula 2 - estagiário 2). Além disso, especificamente o desenvolvimento da quarta aula foi de um conteúdo complexo: "Essa não foi uma boa aula. O conteúdo era muito difícil e eu não estava dominando. Desenvolvi uma atividade que não deixou claro o conteúdo. Os alunos estão sentindo falta do planejamento do semestre e de exercícios para deixar o conteúdo mais claro" (aula 4 estagiário 2), situação que reafirmou as questões anteriormente destacadas.

\section{Planejamento e Organização}

O segundo eixo de análise é o Planejamento e organização. Os cinco indicadores que o compõe podem ser visualizados na Figura 4, em que o primeiro gráfico apresenta as notas do estagiário 1 e o segundo gráfico as notas do estagiário 2 . 
Figura 4 -

Planejamento e organização.

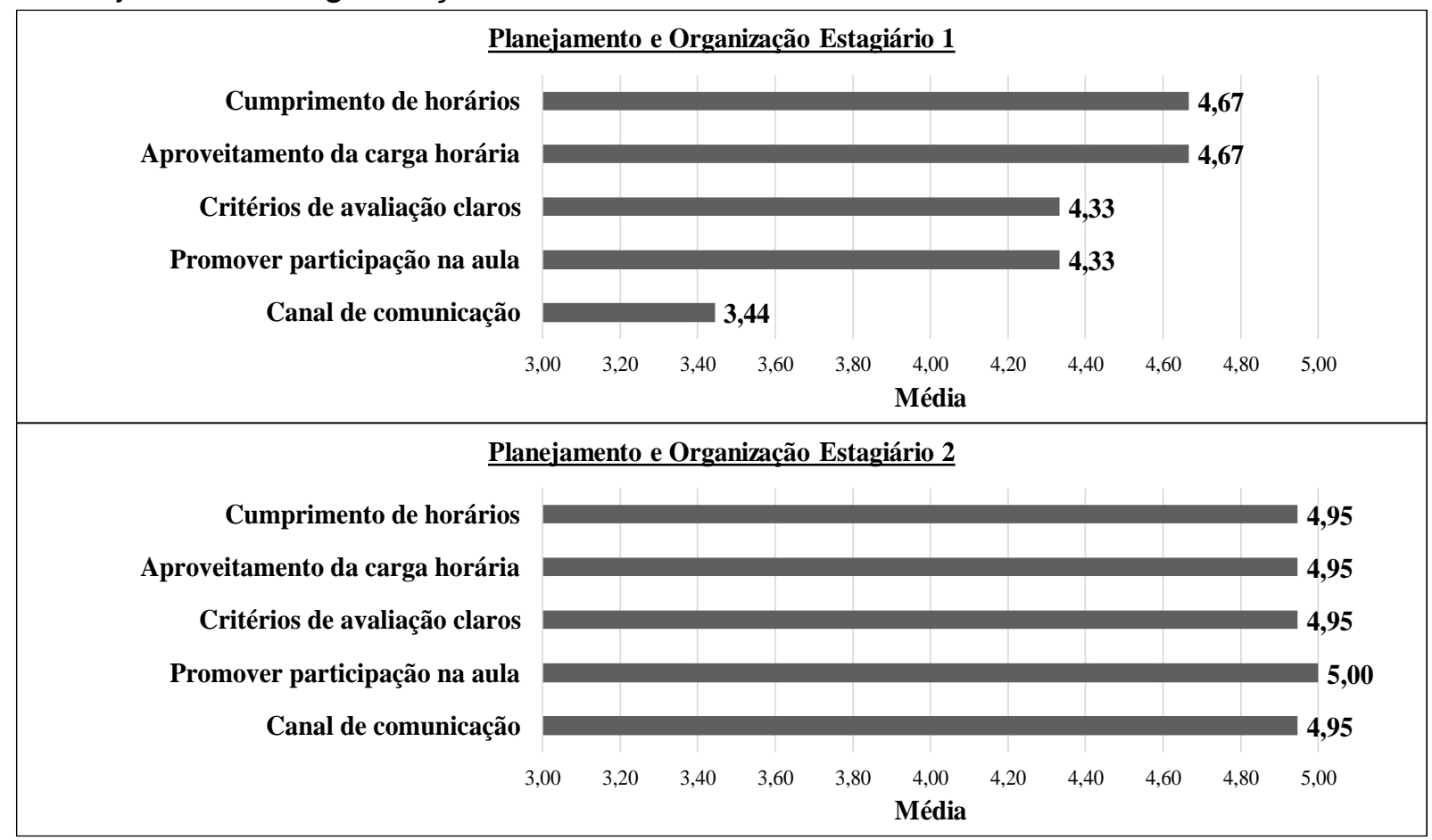

Fonte: dados da pesquisa.

O estagiário 1 iniciou suas atividades no meio do período letivo e os alunos já estavam acostumados com o estagiário anterior, o qual avaliaram, em relatos esporádicos durante as aulas, que poderia apresentar melhorias em diversos aspectos. Mesmo assim, tal fato não se tornou obstáculo para o planejamento e organização do estagiário 1, cujos indicadores "Cumprimento de horários" e "Aproveitamento da carga horária" demonstraram maiores índices de aprovação. Tal fato é revelado no relato que segue: "ao presentar a estrutura de cada aula no início das mesmas, constando dos tempos necessários para cada etapa, e ainda constar de atividades e recursos explícitos, foi possível cativar os alunos e fazê-los compreender em todas as aulas a dinâmica temporal necessária" (aula 4 - estagiário 1).

Em contrapartida, o indicador "Canal de comunicação" ficou prejudicado nesta análise do estagiário 1, ficando abaixo da média. Esse item, após análise atenta das reflexões e avaliações, foi ocasionado por contribuição de ambas as partes. Entretanto, o canal de comunicação dos alunos com o professor titular ou com o estagiário anterior também eram bastante precários, levando a considerar que a turma teria dificuldade com esta ação: "Utilizei da estratégia de comunicação via e-mail, visto ser a que o professor utilizava, porém houve pouquíssima interação na comunicação por este canal por parte dos alunos. A maioria só recebia os arquivos, nem sequer confirmava o recebimento" (aula 3 - estagiário 1). Essa ressalva chama atenção para a necessidade do uso de recursos tecnológicos de comunicação mais adequados ao processo de ensino, como o Moodle, ou o acordo prévio com os alunos de que a interação deve ser realizada, obrigatoriamente, mediante o meio de comunicação escolhido. 
Quanto ao planejamento a avaliação foi positiva para o estagiário 2. Contudo, em relação ao indicador "Critérios de avaliação claros", alguns aspectos se destacam por não resultarem em avaliação positiva, originando o seguinte relato: " $A$ atividade foi desenvolvida por todos com vontade, porém senti que não deixei claro exatamente como deveria ser elaborada. No momento em que sou questionada costumo pegar muito leve, deixando que eles façam as coisas com menos cuidado" (aula 3 - estagiário 2). O que ressalta a valorização do planejamento voltado não somente as propostas avaliativas, mas aos critérios a serem considerados.

No que se relaciona ao indicador "Promover a participação na aula" foi identificada uma contradição, pois os alunos consideraram nota máxima, mas o estagiário relatou que "O grande problema da turma é a falta de iniciativa para a discussão. Isso deve acontecer devido a minha formalidade ao falar. Acredito que o ambiente que eu conduzo é muito formal e associada a uma turma serena, a abertura para a discussão é complicada" (aula 8 - estagiário 2). Essa análise sugere que o estagiário deve buscar compreender a perspectiva do aluno ao mesmo tempo que se percebe refletindo sobre sua própria postura. Talvez o aluno não se sinta convidado a participar das aulas a partir da proposta do professor ou entenda que a sua participação, mesmo que pequena, é sempre efetiva nos momentos solicitados. Ainda, a percepção da autorreflexão pode confundir o professor em formação que, ao compreender a opinião dos alunos, pode promover uma melhor identificação com a futura profissão de professor.

\section{Postura pedagógica}

O terceiro eixo de análise é a postura pedagógica. Os cinco indicadores que o compõe podem ser visualizados na fFigura 5 , em que o primeiro gráfico apresenta as notas do estagiário 1 e o segundo gráfico as notas do estagiário 2.

Figura 5 -

Postura Pedagógica.

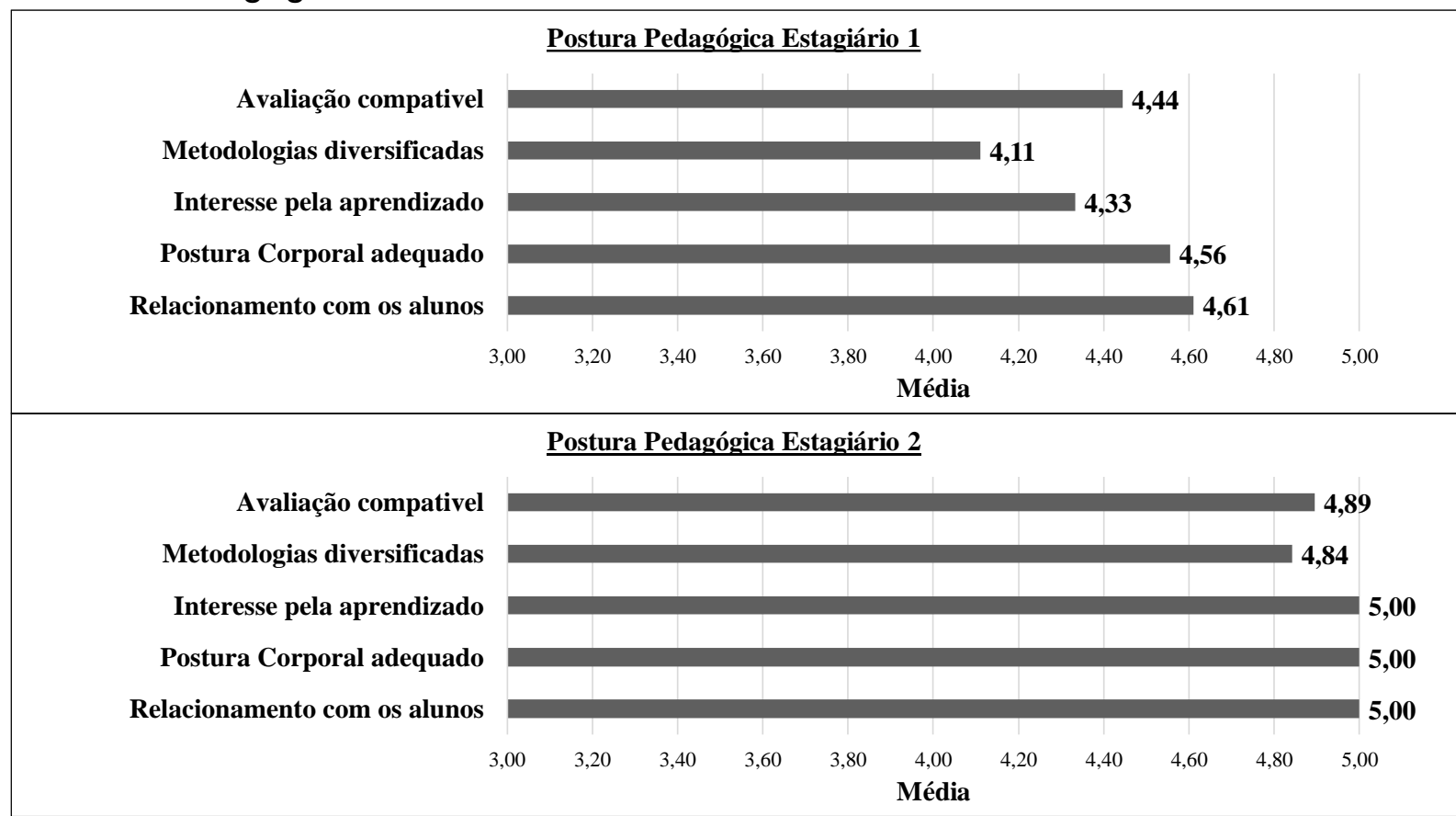

Fonte: dados da pesquisa. 
Para o estagiário 1, os indicadores "Relacionamento com os alunos", a "Postura corporal adequada" e a "Forma avaliativa" sobressaíram-se na perspectiva pedagógica. Conforme já comentado, o estagiário 1 obteve melhor receptividade do que o estagiário que atuou anteriormente junto a turma e por "discussões acerca de artigos sobre as temáticas das aulas visando incentivar os alunos no desenvolvimento de ideias e opiniões e também desinibir os alunos para falar em público" (aula 2 - estagiário 1), houveram atividades diferentes como análises de imagens de postos de trabalho, para simular uma identificação em campo e também atividades de raciocínio lógico integrado ao conteúdo técnico da disciplina. Tais fatores influenciaram na performance positiva de interação com os alunos.

O indicador de "Metodologias variadas" foi percebido pelos alunos com menor qualificação, porém ainda acima da média. Diante dos entraves que ocorreram sobre a mudança de data de início do trabalho do estagiário 1 e das orientações do professor titular, houveram pequenas variações metodológicas a serem implementadas. Mesmo assim as metodologias empregadas foram bem recebidas e realizadas, conforme o relato que segue: "os alunos demonstraram um interesse muito grande pela atividade de caráter prático simulada, que os instigava a analisar fotos de posturas reais de funções de trabalho e usar uma metodologia trabalhada na aula para codificação das posturas e classificação dos níveis de risco" (aula 4 - estagiário 1).

A opinião dos alunos do estagiário 2 quanto à postura pedagógica foi muito boa. Em relação as "Metodologias diversificadas", o estagiário 2 compreendeu que é importante alternar a forma de desenvolver o conteúdo com o passar das aulas, como é o caso dos seguintes relatos: "Foi uma aula boa. Sinto que trazer vídeos e fazer exercícios juntos com eles foi interessante para me integrar com a turma. A maioria tentou participar da elaboração dos exercícios" (aula 6 - estagiário 2) e "Foi uma aula muito dinâmica. 4 grupos tentaram desenvolver o trabalho com cuidado e conhecimento. 2 grupos buscaram o caminho mais fácil, não estavam abertos a melhoria e ficaram tomando mate" (aula 7 estagiário 2).

Os indicadores "Postura corporal adequada" e "Relacionamento com os alunos" podem estar relacionados com a experiência de sala de aula, já que o estagiário 2 apresentou uma melhora desses aspectos nos relatos com o passar das aulas ministradas, como é o caso do relato da aula 10: "Estou a cada dia mais satisfeita com minha fala. Sinto que estou conseguindo falar mais devagar, permitindo que eles consigam entender e até comentar em sala de aula" (aula 10 - estagiário 2). Isso significa que uma boa postura corporal e um bom relacionamento com os alunos permitem uma maior participação dos alunos nas discussões em sala de aula, fatores que contribuem positivamente para promover maior segurança ao professor em formação.

\section{Avaliação do supervisor}

A terceira e última avaliação dos estagiários foi realizada pelo supervisor de estágio. O supervisor é o professor titular das disciplinas, que foi o mesmo para ambos estagiários. Ele acompanhou todo o estágio, desde o planejamento à execução das aulas 
e atribuiu notas de 0 a 10 aos indicadores para os quatro eixos de avaliação: (1) Domínio do conhecimento na área específica de atuação; (2) Planejamento de situação de ensino; (3) Comunicação; (4) Compromisso. Ambos estagiários foram avaliados com média superior a 9,0.

Analisando o estagiário 1 o supervisor recomendou que utilizasse mais de atividades multimídias - vídeos técnicos, reportagens, exemplos práticos - pois, segundo sua experiência, surte melhor efeito no processo de memorização dos estudantes do curso técnico. A maioria não dedicava tempo suficiente a leitura e estudo em horários extraclasse. Entretanto, criou-se um trade off, pois a exposição de uma carga significativa e necessária de conceitos teóricos e técnicos requeria a exposição textual e dialogada. Dessa forma, um ponto de melhoria é em relação a necessidade de instigar os alunos do curso técnico a transgredirem a limitação de horas de estudo extraclasse. Isso pode ser feito por incentivos coordenados com outras disciplinas, com o departamento pedagógico da escola técnica e com a orientação e supervisão integradas no uso de recursos de apoio ao estudante, como as plataformas interativas de educação a distância.

Para o supervisor o estagiário 2 poderia ter explorado mais o relacionamento dos conteúdos didáticos ao cotidiano de um técnico em segurança do trabalho. Esse tipo de exemplo prático, na perspectiva do professor supervisor, é importante para conceituar os conteúdos e trazer curiosidade aos alunos. O outro ponto a melhorar está associado ao eixo de planejamento de situação de ensino em que o estagiário 2 nem sempre planejou todas as aulas com uma antecedência que permitisse tempo disponível para alteração pelo supervisor. Esse aspecto é importante, pois tudo o que é planejado deve ser submetido ao supervisor com antecedência, o que sempre foi realizado, mas o período de antecedência a realização das aulas poderia ter sido maior. Assim, esse período poderia ser utilizado para discussão de melhorias das metodologias e trabalhos elaborados para as aulas.

\section{Considerações finais}

Neste trabalho se propôs a apresentar e discutir a avaliação da performance de dois estagiários do Programa Especial de Graduação de Formação de Professores para Educação Profissional e Tecnológica da Universidade Federal de Santa Maria, na realização da principal etapa do curso, o Estágio Supervisionado de Ensino III. Os estágios ocorreram nas disciplinas de Ergonomia e Administração e Organização do Trabalho, ambas do Curso Técnico Subsequente em Segurança do Trabalho do Colégio Técnico Industrial de Santa Maria, porém em semestres e turmas de alunos diferentes.

A possibilidade de cursar o PEG propiciou a compreensão da atuação e das responsabilidades concernentes ao profissional docente. O contato com professores proporcionou aos estagiários a experiência do ambiente de trabalho para além da sala de aula, o que permitiu reflexões e diálogos sobre conteúdos e trabalho colaborativo, incluindo a direção da instituição, técnicos administrativos e a comunidade acadêmica. Esses fatores do quotidiano docente estagiado impactaram positivamente os estagiários, causando crescimento pessoal e profissional de ambos.

Do ponto de vista acadêmico considera-se o estudo como relevante ferramenta de reafirmação de práticas (Vieira, 2009; Milanesi, 2012; Juklová, 2015), corroborando para os ideais dos mesmos de que a prática investigativa e reflexiva sobre a própria atuação é 
fundamental. Afirma-se que a realização de auto-avaliação e da utilização de mecanismos de reflexão paralelos ao desenvolvimento das atividades docentes são atividades necessárias e devem ser incentivadas. Tal argumento corrobora o trabalho de Lobato e Quadros (2018), no qual a vivência reflexiva proporciona transformações no entendimento desses professores em formação que refletirão em suas práticas quando assumirem a docência.

Mesmo considerando o aspecto subjetivo de uma avaliação aplicada diretamente pela parte envolvida, pela amplitude na interpretação das questões pelos respondentes e o comprometimento com respostas pertinentes e verídicas que comprovem um feedback o mais realista possível, do ponto de vista prático, e tendo em vista os resultados positivos das avaliações, vislumbrou-se que o cenário futuro para os estagiários, do curso de formação de professores em questão, está sendo delineado pela experiência de estágio de forma efetiva e eficaz.

A evolução intelectual e profissional é evidente, pois os alunos estagiários desenvolveram novas habilidades relacionadas a postura pedagógica de trabalho, a comunicação com diversos níveis hierárquicos de uma instituição de ensino e aos entraves corriqueiros do exercício contínuo de ensino e aprendizagem. Diante de todo processo de formação pedagógica os estagiários compreenderam como positiva a experiência e que o desafio de realizarem o estágio foi realizado com muita dedicação e trouxe retornos importantes.

\section{Referências}

BRASIL. Lei $n$. 11.788, de 25 de setembro de 2008. Dispõe sobre o estágio de estudantes. $2008 . \quad$ Disponível em http://www.cvm.gov.br/export/sites/cvm/menu/acesso_informacao/servidores/estagios. Acesso em 11 nov. 2018.

BRASIL. Resolução n. 02, de 16 de junho de 1997. Dispõe sobre programas especiais de formação pedagógica de docentes para as disciplinas do currículo do ensino fundamental, do ensino médio e da educação profissional em nível médio. Disponível em http://portal.mec.gov.br/setec/arquivos/pdf/Res02.pdf. Acesso em 11 nov. 2018.

CASTAMAN, Ana Sara; VIEIRA, Alboni Marisa Dudeque PianovsKI; OLIVEIRA, Denise. A constituição da profissão docente: um estudo com professores da educação profissional. Revista Diálogo Educacional, v. 16, n. 50, 2016, p. 20 . Disponível em https://periodicos.pucpr.br/index.php/dialogoeducacional/article/view/2911/2833. Acesso em 12 nov. 2018.

CAZETTA, Valéria; DOMINGUEZ, Celi Rodrigues Chaves; PIOKER-HARA, Fabiana Curtopassi; CUBERO, Josely. Educar o olho e o olhar: narrativas audiovisuais, contextos escolares e estágios curriculares supervisionados. Educação \& Pesquisa, v. 44, 2018, p. $1-21$.

CTISM. Projeto político-pedagógico do Curso Técnico em Segurança do Trabalho. Santa Maria: Ctism, 2018. Disponível em http://www.ctism.ufsm.br/cursos/educacaoprofissional/seguranca-do-trabalho. Acesso em 12 nov. 2018. 
FREIRE, Paulo. A pedagogia da autonomia: saberes necessários à prática educativa. Rio de Janeiro: Paz e Terra, 1996.

JUKLOVÁ, Kateřina. Reflection in Prospective Teacher Training. Procedia - Social and Behavioral Sciences, v. 171, 2015, p. 891-896 Disponível em <http://www.sciencedirect.com/science/article/pii/S1877042815002360. Acesso em 12 nov. 2018.

LOBATO, Anderson Cezar; QUADROS, Ana Luiza de. Como se constitui o discurso de professores iniciantes em sala de aula. Educação \& Pesquisa, v. 44, 2018, p. 1-21.

MACHADO, Simone Cristina. Perspectivas do professor sobre a sua prática docente. CONGRESSO NACIONAL DE EDUCAÇÃO, 7, 2007. Anais... Curitiba: PUCPR, 2007.

MILANESI, Irton. Estágio supervisionado: concepções e práticas em ambientes escolares. Educar em Revista, n. 46, 2012, p. 209-227, 2012. Disponível em http://www.scielo.br/pdf/er/n46/n46a15.pdf. Acesso em 9 nov. 2018.

PACHANE, Graziela Giusti; PEREIRA, Monteiro De Aguiar Pereira. A importância da formação didático-pedagógica e a construção de um novo perfil para docentes universitários. Revista lberoamericana de Educación, v. 35, n. 1, p. 1-13, 2004. Disponível em https://rieoei.org/RIE/article/view/2925. Acesso em 9 nov. 2018.

ROCHA, Karla Marques Da; ABEGG, Ilse; RELA, Eliana. Orientação de estágio: uma experiência na formação de docentes. Educação, v. 40, n. 1, 2015, p. 117-130. Disponível em http://www.redalyc.org/html/1171/117132892009. Acesso em 9 nov. 2018.

SCREMIN, Greice; ISAIA, Silvia Maria De Aguiar. Pedagogias universitárias: as influências das diferentes áreas do conhecimento na atuação docente. Educação \& Pesquisa, v. 44, 2018, p. 1-18.

SPEAR, Anee Marie; COSTA, Romina Bobbio da. Potential for transformation? Two teacher training programs examined through a critical pedagogy framework. Teaching and Teacher Education, v. 69, 2018, p. 202-209, 2018. Disponível em http://www.sciencedirect.com/science/article/pii/S0742051X16308915. Acesso em 9 nov. 2018.

TARHAN, Ozge. The State of In-Service Training of Teachers and Teacher Training in National Education Councils. Procedia - Social and Behavioral Sciences, [s. I.], v. 197, 2015, p. 378-381

UFSM. Projeto político-pedagógico do Programa Especial de Graduação de Formação de Professores para a Educação Profissional. Santa Maria: UFSM, 2015. Disponível em https://ead08.proj.ufsm.br/moodle2_UAB/mod/folder/view.php?id=44175. Acesso em 9 nov. 2018.

VIEIRA, Flávia. Para uma visão transformadora da supervisão pedagógica. Educação \& Sociedade, v. 29, n. 105, 2009, p. 197-217. 
Paula Donaduzzi Rigo é estudante do curso de doutorado em Engenharia de Produção na Universidade Federal de Santa Maria.

Orcid: https://orcid.org/0000-0001-7814-1792.

Endereço: Av. Roraima, 1000 - 97105-900 - Santa Maria - RS - Brasil.

E-mail: pauladonaduzzi@gmail.com.

Rafael Marcuzzo é estudante no curso de doutorado em Engenharia de Produção na Universidade Federal de Santa Catarina.

Orcid: https://orcid.org/0000-0003-2926-5670.

Endereço: Rua Engenheiro Agronômico Andrei Cristian Ferreira, 30 - 88040-900 Florianópolis - SC - Brasil.

E-mail: rafael.marcuzzo@gmail.com.

Aruna Noal Correa é doutora em Educação pela Universidade Federal do Rio Grande do Sul e professora na Universidade Federal de Santa Maria.

Orcid: https://orcid.org/0000-0001-5954-8167.

Av. Roraima, 1000 - 97105-900 - Santa Maria - RS - Brasil.

E-mail: arunanoal@hotmail.com.

Recebido em 15 de junho de 2019.

Aceito em 23 de agosto de 2019.

(c) (i) 